\title{
MONITORING DIAGNOSTIC INDICATORS DURING OPERATION OF A PRINT MACHINE
}

\author{
Jozef Dobránsky' ${ }^{1}$ Petr Baron' ${ }^{1}$, Marek Kočiško', Monika Telišková' \\ 1 Faculty of Manufacturing Technologies with a seat in Prešov, Technical University of Košice, Štúrova 31, 080 \\ 01 Prešov, Slovak Republic, e-mail: jozef.dobransky@tuke.sk
}

Received: 2015.10.09

Accepted: 2015.11.14

Published: 2015.12.04

\begin{abstract}
This article deals with monitoring diagnostic indicators during the operation of a machine used for production of packing materials with a print. It analyses low-frequency vibrations measured in individual spherical roller bearings in eight print positions. The rollers in these positions have a different pressure based on positioning these rollers in relation to the central roller. As a result, the article also deals with a correlation of pressure and level of measured low-frequency vibrations. The speed of the print machine (the speed of a line in meters per minute) is a very important variable during its operation, this is why it is important to verify the values of vibrations in various speeds of the line, what can lead to revelation of one or more resonance areas. Moreover, it examines vibrations of the central roller drive and measurement of backlash of transmission cogs of this drive. Based on performed analyses recommendations for an operator of the machine have been conceived.
\end{abstract}

Keywords: print machine, vibrations, gear box, downforce.

\section{INTRODUCTION}

Vibration is a very important aspect to be considered during the design of all kinds of engineering systems. In general, there are two kinds of vibration. The first is where the vibration is undesirable and should be either mitigated, or its effects on people or systems should be minimized. Examples include suspension design of automobiles and shock mounts on sensitive devices. The second is where vibration is introduced intentionally. Examples are musical instruments discussed above, massagers and similar devices, signaling devices, such as the vibrators in cell phones, etc. Of the two, the first aspect is much more important. It is also important to remember that oftentimes, vibration of a system can lead to damage or destruction, and hence may need to be reduced or eliminated, even if we are not concerned with the immediate effect on the surrounding systems or people [1,2].

The quantity of vibration that is tolerable depends on the measured system. In an earthquake, vibration of a few feet might be permissible, de- pending on the flexibility of the structure. In a car, or a bridge, vibrations of many inches might be tolerated. However, finely tuned gas turbine rotors in aircraft engines, for example, can be destroyed by excessive vibration (in this case, excessive can mean as little as $50 \mu \mathrm{m}$ ). In sensors and microactuators, vibrations have to be limited to micrometres for successful operation $[3,4]$.

What is not very obvious is the usage of vibration as a "friend." Let us take the example of a very complicated machinery, such as a gas turbine system. It is an expensive and dangerous system that we do not want to fail. In other words, we would really like an early predictive system that will tell us if the system has some defects or problems, i.e., if unchecked, it could go on to destroy the machine in a catastrophic manner, resulting in tremendous loss of money and equipment, and possibly, even human lives. Well, this is where vibration comes in as an early warning system. It turns out that, for most problems, vibration is often an early indicator, and is often easier to measure and analyse than something 
like pressure. Vibration signals also tend to have richer data with more information about the state of the machine than other quantities such as temperature and pressure $[5,6]$.

\section{MEASURING METHODS}

Following methods were used to evaluate the vibrations in the low frequency range:

- velocity measurement technique (vibration speed), measuring unit: $\mathrm{mm} / \mathrm{s}$, RMS detection;

- as recommended by ISO 10816-3, FFT spectrum for the frequency range $10-800 \mathrm{~Hz}$;

- enveloping acceleration measurement technique, measuring unit: Eg, PtP detection, for the frequency range $50-1000 \mathrm{~Hz}$, FFT spectrum and time record.

The following methods were used to evaluate the vibrations in the high frequency range:

- acceleration measurement technique (vibration acceleration), measuring unit: g, PtP detection, frequency range up to $16 \mathrm{kHz}$, FFT spectrum and time record;

- enveloping acceleration measurement technique, measuring unit: Eg, PtP detection, fre- quency range up to $10 \mathrm{kHz}$ and up to $20 \mathrm{kHz}$, FFT spectrum and time record [7].

The following methods were used for the evaluation within the field of acoustic emission and ultrasound:

- see measurement technique (SKF), measuring unit: See, PtP detection, frequency range up to $600 \mathrm{kHz}$, FFT spectrum and time record;

- HFD (SKF) measuring method, oscillation (acceleration) analysis in the frequency range of $40 \mathrm{kHz}$;

- the measurement technique is used to evaluate the lubrication, load capacity of the oil film, metal contact, jamming and the abrasion (wear) of the contact surfaces (bearings and gearing) [8].

\section{EVALUATION}

Diagrams (Fig. 1 and Fig. 2) present the downforce in the individual downforce positions. The impact of downforce is always horizontal. Regarding the position of valves no. 1, 4, 5 and 8, the downforce on the aforesaid valves is higher in comparison to other valves.

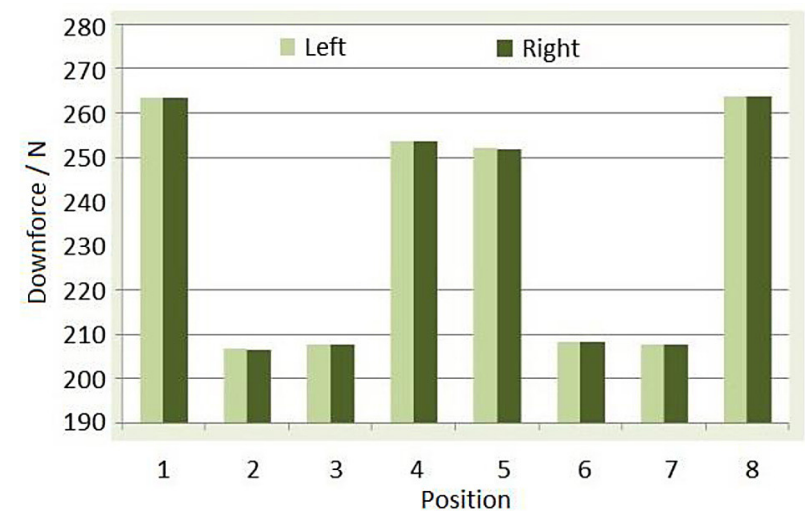

Fig. 1 Downforce on the anilox rolls in different positions

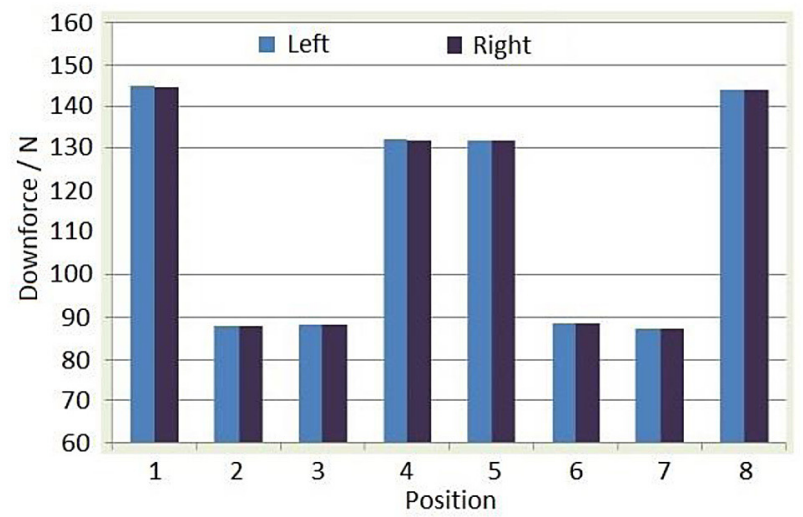

Fig. 2. Downforce on the plate in different positions 
Based on the summation values recorded (diagrams in Fig. 3 and Fig. 4), we can conclude that positions no. 3, 4, 6 and 8 exhibit increased mechanical vibrations.

\section{Comparison of positions no. 2 and 4 at various rpm}

In Figures 5 and 6, difference in levels of summation values of different courses is visible. Measurement of courses was carried out at the velocity (of the line) from 50 to $250 \mathrm{~m} / \mathrm{min}$ and back to $50 \mathrm{~m} / \mathrm{min}$. Position no. 4 exhibits the mechanical vibrations twice as high as position no. 2. In position no. 2 , we discovered the resonance zone between the velocity of 185 and $245 \mathrm{~m} / \mathrm{min}$, reaching the maximum at $215 \mathrm{~m} / \mathrm{min}$.

\section{Drive of the central valve}

Recorded values listed in the table show that gearbox is the only troubled node (point 4 , to be exact). The attempt to extract oil (transmission fluid) sample from the gearbox failed for there was almost no oil left. The transmission fluid was subsequently refilled. However, the oil did not re- main inside the gearbox for a very long time and it leaked out. Following diagrams document the state of the HF vibrations in point 4 during the aforesaid states of the oil in the gearbox.

The records (Fig. 7, Fig. 8 and Fig. 9) contain significant amplitudes (several decuples) indicating the mechanical or tribotechnical problem. That was the reason why we proceeded with the physical check of the transmission gear. We checked the clearance as well as possible damage of the gear (pitting). Average clearance recorded was $0.5 \mathrm{~mm}$, what suits the tolerance zone ( 0.3 to $0.6 \mathrm{~mm}$ ). We found no visually recognisable damage on the individual cogs.

\section{MONITORING OF THE CLEARANCE OF CENTRAL GEAR}

Previous diagnostic vibration measurements performed by this machine showed that the values of the vibrations in the field of the propulsion of the central valve are above the permitted level of ALARM 2 - Danger. While evaluating the origin of such a state, the possibility of the

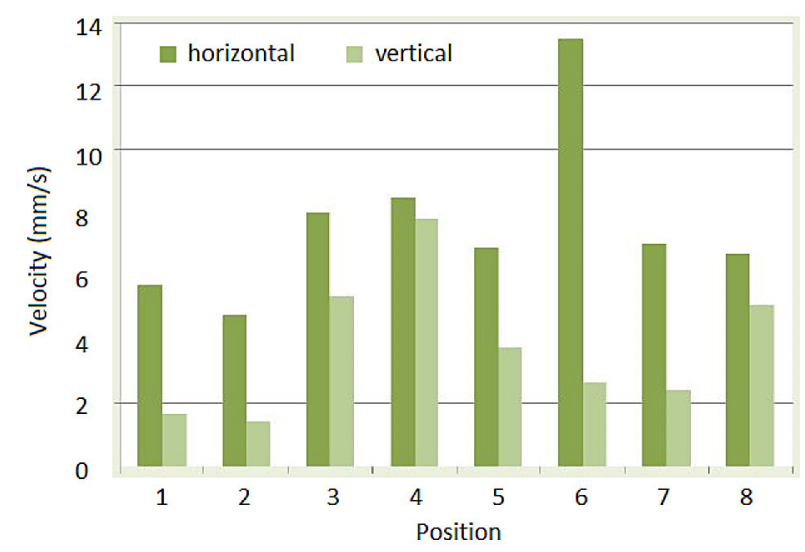

Fig. 3. The measured value of velocity on individual positions

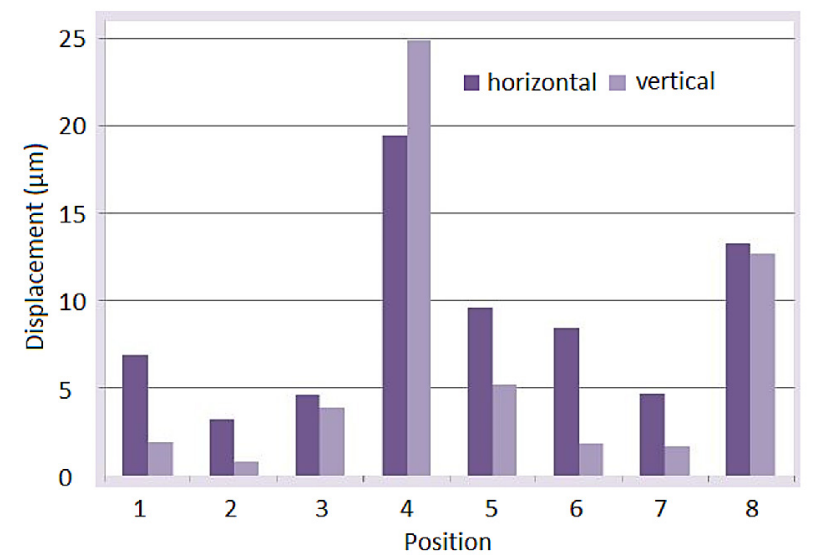

Fig. 4. The measured value of displacement on individual positions 


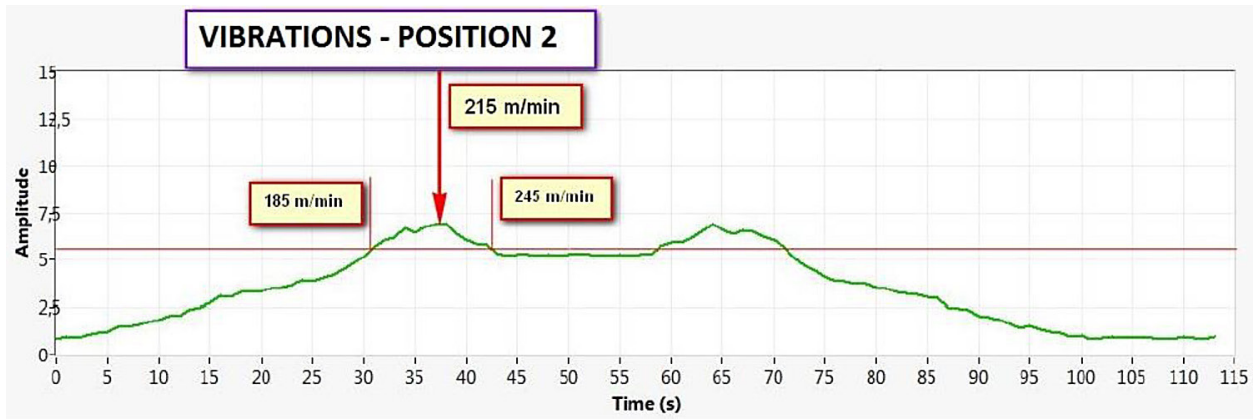

Fig. 5. The course of vibration velocity to position 2

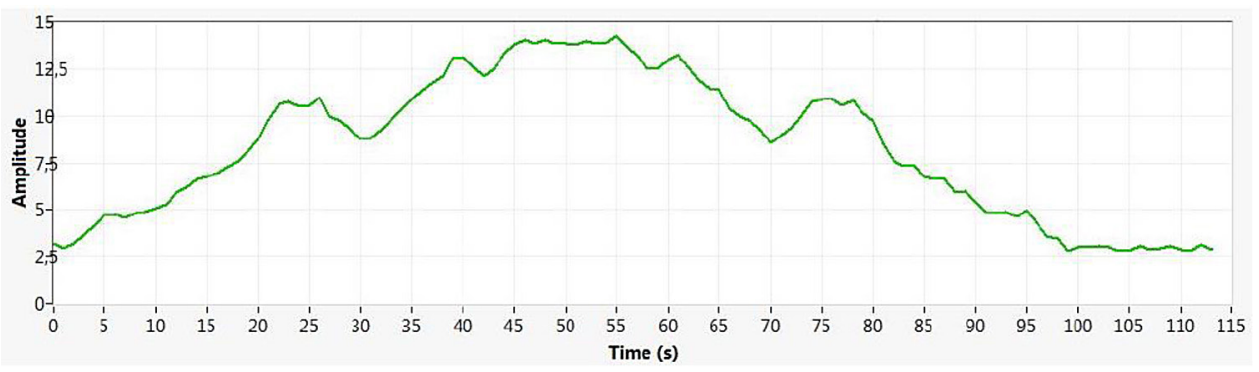

Fig. 6. The course of vibration velocity to position 4

Table 1. The measured values of vibrations to drive a central cylinder

\begin{tabular}{|c|c|c|c|c|}
\hline \multirow{2}{*}{ Measuring point } & \multicolumn{3}{|c|}{ Measured values } & \multirow{2}{*}{ Evaluation } \\
\cline { 2 - 5 } & Velocity [mm/s] & Acc [g] & HFAcc [gE] & suitable \\
\hline 1H engine & 1.53 & 1.10 & 4.50 & suitable \\
\hline 1V engine & 1.18 & 1.19 & 3.14 & suitable \\
\hline 2H engine & 0.76 & 1.56 & 4.85 & good \\
\hline 2V engine & 1.05 & 1.40 & 1.73 & suitable \\
\hline 3V gearbox & 0.58 & 1.89 & 4.28 & not suitable \\
\hline 4H gearbox & 0.61 & 4.34 & 11.71 & not suitable \\
\hline 4V gearbox & 1.57 & 1.86 & & \\
\hline
\end{tabular}

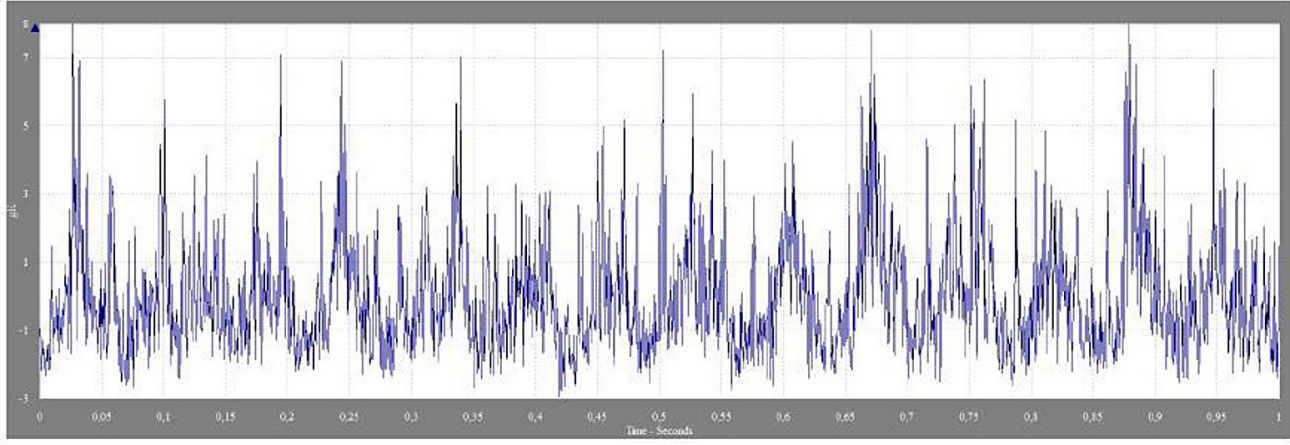

Fig. 7. Time recording HFAcc in point $4 \mathrm{H}$ (before oil-filling)

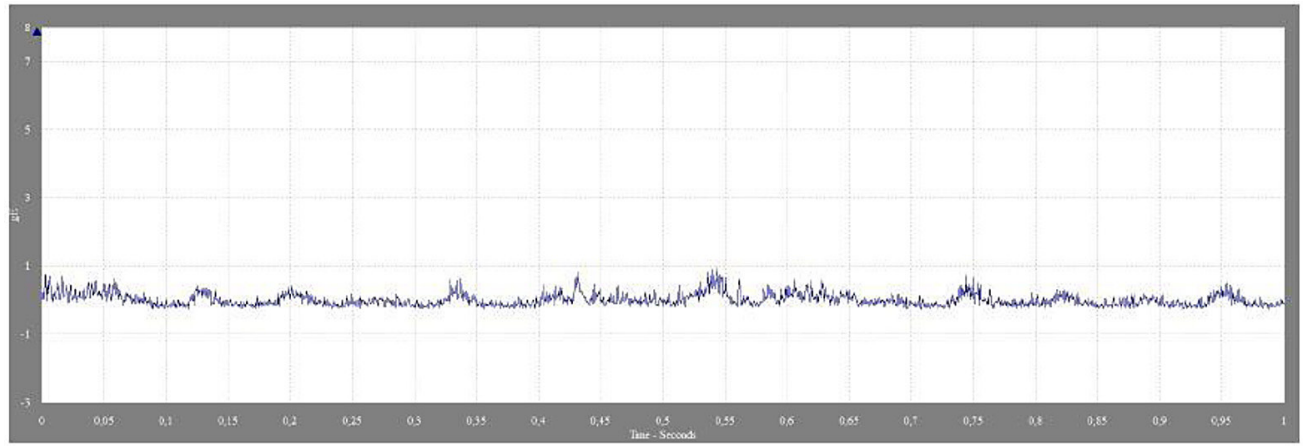

Fig. 8. Time recording HFAcc in point $4 \mathrm{H}$ (after oil-filling) 


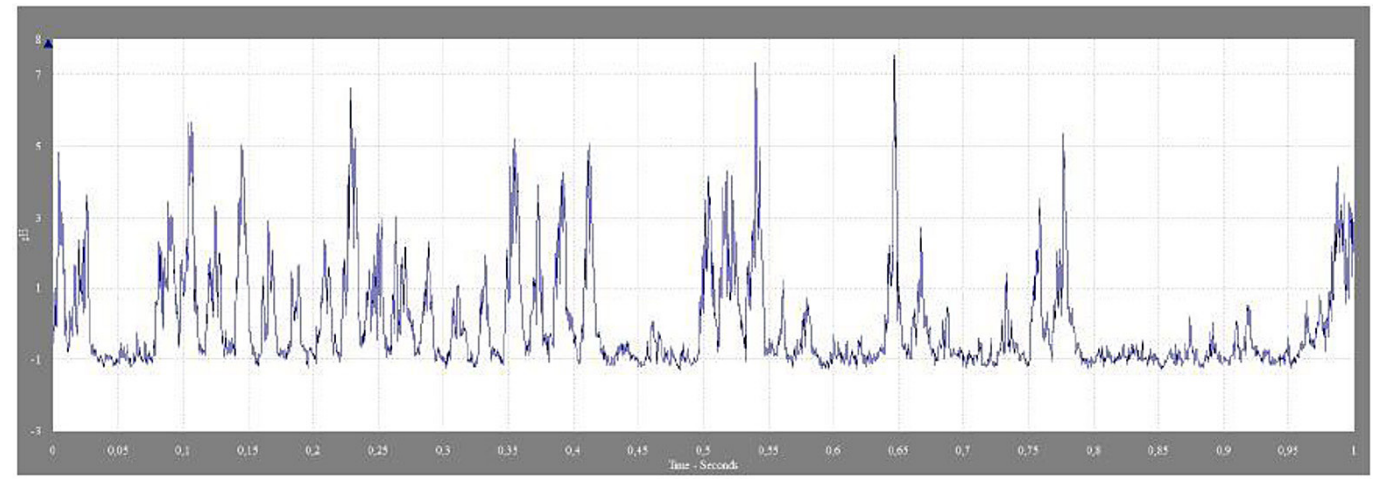

Fig. 9. Time recording HFAcc in point $4 \mathrm{H}$, a few days after oil-filling (oil spilled through the damaged seal)

increased gear clearance at the open front gear of the coupling between the propulsion and the main valve became one of the causes identified. In was therefore necessary to either carry out a measurement, or adjust the clearance.

\section{Description of the organisation of the machine's main valve propulsion}

Main valve of the machine is propelled by the propulsion in form of open front gear. The propulsion consists of the DC motor connected to the single-stage planetary gear via clamp-type coupling with the pinion gear attached to its output shaft situated inside the housing. All the parts of this propulsion are connected into one whole, which is mounted on the machine frame. The slide fitting of the aforesaid whole in the machine frame enables the adjustment of the gear clearance of the open front gear.

Geometric parameters of the cogs of the open front gear:

- Type of gear: front gear with straight cogs (teeth), $\alpha=20^{\circ}$.

- Normal module of gear: $\mathrm{m}=3.0 \mathrm{~mm}$.

- Number of teeth of driving pinion: $z 1=60$.

- Number of teeth of propelled wheel: $\mathrm{z} 2=712$.

- Transmission ratio: $\mathrm{i}=11.86$.

- Axial distance: $\mathrm{a}=1.158 \mathrm{~mm}$.

- Gear clearance: $\mathrm{j}=0.377$ to $0.663 \mathrm{~mm}$ - values of the gear clearance were calculated via KISSsoft software.

\section{Measurement method used}

In this case, the measurement method of the rotation of one of the $\operatorname{cog}$ wheels of the evaluated gear engaged was used to measure the gear clearance. The micrometer dial with hundredth subdivision was used to perform the measurement. Its bezel clamp was located on the pitch circle of the gearing of the propelled wheel. Second engaged cog wheel, in this case the driving pinion, was blocked to prevent it from turning during the measurement. For the rotation is measured on the pitch circle of the gear, recorded value directly represents the gear clearance in [mm].

Measurement of the gear clearance is usually performed in several measuring points located on the perimeter of the cog wheel in order to find out whether the deformations influence the decrease or removal of the clearance and, vice versa, whether the excessive wear of the gearing causes the enormous increase in the gear clearance in question. Measurement of the gear clearance is, at the same time, combined with the visual examination of the gearing. The aim of this measurement is to discover whether there are any traces of the increased mechanical wear or pitting present. In case the variable gear clearance is discovered, the measurement of the so-called measurement over teeth and measurement of radial run of the gearing is included within the measurement of the gear.

\section{State of the front gearing discovered by the examination and recorded values of the gear clearance}

Visual examination of the gearing, measurement of the gear clearance and listening to the operation of the front gearing in question revealed the following:

- Toothing of the propelled gear is in good shape, no signs of excessive wear or pitting were present.

- Excessive gear clearance reaches the value of $\mathrm{j}=0.5 \mathrm{~mm}$. This value is situated in the middle of the tolerance zone of the permitted level of gear clearance determined by the KISSsoft calculation software.

- Additional listening proved that the operation of evaluated front gearing was still and regular 
with no impacts. Constant tone pitch shows that there is no variable gear clearance or its local removal happening at the evaluated gear positioned around the perimeter of the propelled wheel.

\section{CONCLUSIONS}

Basing on the measurements and analyses performed, we can conclude the following:

1. Measurement of the vibrations of the valves in downforce positions revealed several problematic positions; specifically positions no. 3 , 4, 6 and 8.

2. Moreover, we observed the resonance zone with increased summation value of the LF vibrations at the position no. 2; this zone ranges between the velocity values from $185 \mathrm{~m} / \mathrm{min}$ to $245 \mathrm{~m} / \mathrm{min}$.

3. Measurement of the vibrations of the central valve propulsion revealed high values of the HF vibrations on the transmission of the propeller; neither the damage of the cogs nor the increased gear clearance were confirmed; the transmission suffers from the lack of oil that leaked out several days after it was refilled.

Basing on the analysis performed, we can conclude that the state of the front toothed gearing does not imply that the gearing could cause excessive vibrations. Recorded values of the gear clearance are in compliance with recommended values, therefore, there is no need to correct them.

\section{Recommendations}

We recommend checking the wear of the housings accommodating the bearings at the po- sitions with high values of mechanical vibrations, discover and eliminate the cause of the oil leaking from the gear box.

\section{Acknowledgment}

Ministry of Education, Science, Research and Sport of SR supported this work, contract VEGA No. 1/0032/12 and ITMS project 26220220125.

\section{REFERENCES}

1. Nataraj C. Vibration of mechanical systems. Lightning Source, Hampshire 2011.

2. Valent O., Galád M., Kačmár L. Technical diagnostics, vol. 1. Condition monitoring and maintenance systems, p. 43.

3. Stejskal T., Kováč J., Valenčík Š. Mechanism of randomness in vibration signals of machinery. Applied Mechanics and Materials, 282, 2013, 257-262.

4. Šebo J., Buša J., Demeč P., Svetlík J., Optimal replacement time estimation for machines and equipment based on cost function. Metalurgija, 52(1), 2013, 119-122.

5. Panda A., Prislupčák M. Analysis of technological factors. Studia i materialy, 34(1), 2014, 13-16.

6. Michalik P., Zajac J., Hatala M., Hutyrová Z., Mital' D., Olhova J. Comparison measurement of the distance between axes of holes with the roundtest RA120 and Thome Präzision-Rapid. Applied Mechanics and Materials, 616, 2014, 284-291.

7. Greškovič F., Dulebová L., Duleba B., Sikora J.W. Evaluation of process wear of selected tool steels for injection molds. Advanced Materials Research 739, 2013, 171-176.

8. Sobotka J., Solfronk P., Doubek P. Using contactless optical systems to characterize and measure deformation of TWIP materials. Physics Procedia, $22,2011,2-7$.

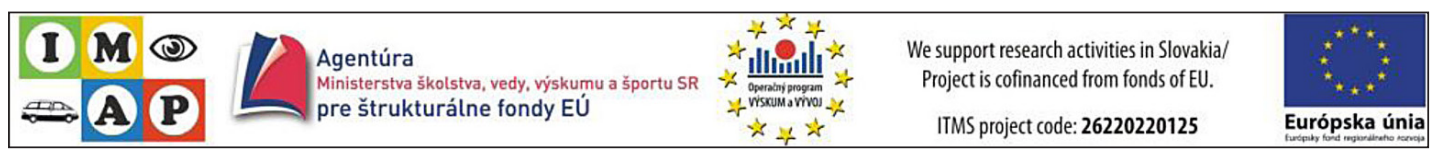

